\title{
Culture, Religion and the State: Towards a Multidisciplinary Approach to Ensuring Public Health During the COVID-I9 Pandemic (and Beyond)
}

\author{
Ivan Efreaim Gozum (D) \\ Harvey Gain Capulong' \\ Jose Ma Gopez \\ Joseph Renus Galang ${ }^{2,3}$ \\ 'Center for Christian Formation and \\ Praxis, Angeles University Foundation, \\ Angeles City, 2009, Philippines; \\ ${ }^{2}$ Graduate School, Angeles University \\ Foundation, Angeles City, 2009, \\ Philippines; ${ }^{3}$ Theology and Religious \\ Education Department, De La Salle \\ University, Manila, 0922, Philippines
}

Correspondence: Ivan Efreaim Gozum Email gozum.ivanefreaim@auf.edu.ph

\begin{abstract}
Background: This research investigates different approaches by cultural, religious and political groups in ensuring public health during the COVID-19 pandemic. During the pandemic, several methods were done by governments and healthcare institutions to mitigate the spread of the virus.

Methods: This study uses content analysis, specifically a literature review, on existing online literature found in online journals, books, and reports relevant to the COVID-19 pandemic. The paper presents the available qualitative data including substantive findings as well as theoretical and methodological foundations relevant to the topic.

Results: Culture, religion and the state have roles to play in ensuring public health during the COVID-19 pandemic. These three areas can help in mitigating the transmission of the virus, managing patients, and aiding the rollout of COVID-19 vaccines.

Conclusion: This paper ends by suggesting that, in ensuring public health during the COVID-19 pandemic, a multidisciplinary approach, involving a concerted effort among culture, religion and the state, is necessary. This approach is also recommended for any public health crisis in the future.
\end{abstract}

Keywords: COVID-19, multidisciplinary approach, culture, religion, state

\section{Introduction}

As the coronavirus is non-discriminating, so must the proper response also be allencompassing. For more than a year, the whole world has been pestered by the outbreak of COVID-19. Since its outbreak caused alarming levels of spread, severity, and inaction, the World Health Organization (WHO) declared it a pandemic in March 2020. ${ }^{1}$ This virus, SARS-CoV-2, is deemed as severe because its transmission is through respiratory droplets which can survive in the air and in asymptomatic carriers. ${ }^{2}$ For this reason, many countries responded by preserving their health service and treating patients who contracted the virus. ${ }^{3}$ Moreover, preventive measures were implemented by different leaders, such as hand hygiene, social distancing, and selfisolation, ${ }^{2}$ including travel bans, to mitigate the spread of the coronavirus. Thus, this virus truly affected the way people live just to put a halt to its spread.

This health crisis challenged the way healthcare institutions ensure public health. As the science which promotes the protection and health of communities, different approaches are to be done for this pandemic to come to an end. One of these approaches is the use of informatics. In collecting and communicating health information, social media and other communication tools were used by institutions 
to spread awareness on what to do to avoid contracting the virus and to be informed about the cases in their respective areas. ${ }^{4}$ Also, infographics were utilized since they engage a valuable and versatile way of advocating public health, closing critical health literacy gaps, and inspiring all patient communities to be socially responsible. ${ }^{5}$

In addition, quarantine periods during the COVID-19 pandemic caused a psychological burden for those who cannot participate in social activities, which leads to an increase in anxiety, depression, and distress. ${ }^{6}$ This concern urges healthcare professionals to also act towards maintaining the mental health of the people. ${ }^{7,8} \mathrm{~A}$ previous article emphasized that healthcare professionals themselves need psychospiritual care since they are wounded healers. ${ }^{9,10}$ Also, work-from-home employees and educators need psychosocial support since they perceive no demarcation between work and home. ${ }^{11}$ Lastly, even quarantined individuals and their families must have psychospiritual care since the trauma that the virus gave them is difficult to get by. ${ }^{12}$

Moreover, another problem that stemmed from the COVID-19 pandemic concerns the economic situation of some countries. The least advantaged members of a country must be prioritized in order for them to cope up with the difficulties they experience during the pandemic. ${ }^{13,14}$ Also, a previous study presented that those who were most affected by the virus are the ones from low-income families. ${ }^{15}$ With this, communities who face poverty, lack access to healthcare, and are densely populated, must be given focus by the government to mitigate the transmission and help them survive in these trying times. ${ }^{16}$ Lastly, since vaccinations are already done around the world, it is essential that healthcare professionals must promote it to ensure public health. However, there is hesitancy ${ }^{17}$ among people, including medical students. ${ }^{18}$ To ensure the effectiveness of the vaccines, both healthcare professionals and government officials should build public trust in order to promote vaccination. ${ }^{19}$ Hence, if vaccination is promoted, we are close to ensuring proper public health.

The COVID-19 pandemic is primarily a public health crisis, but a proper response to see its end requires concerted effort with other fields. Recognizing the different approaches in solving the problems that the COVID-19 pandemic brought, it is important to recognize the role of other fields in helping mitigate the virus' transmission, manage patients, and promote available vaccines. In this paper, we will discuss the roles of culture, religion and the state in combating this health crisis.

\section{Stages of a Public Health Crisis}

Since the COVID-19 pandemic caused a public health crisis around the world, it is essential for us to look at the roles of culture, religion and the state toward COVID19 transmission, management, and vaccination.

\section{Transmission}

The first case of COVID-19 was reported on December 31, 2019, in Wuhan, China. At first, so little was known about the virus. In fact, WHO labeled it as cases of pneumonia of an unknown etiology. ${ }^{20}$ The lack of information about an unseen virus has caused the world to react in different ways. In this situation, culture, religion and the state play crucial roles in preventing the virus from spreading since they have the power to alter and influence people's behavior.

One of the reasons why the virus spread like wildfire is due to the fact that, prior to the pandemic, people lacked awareness that such a thing exists or might exist since it was not part of the common culture; hence, most were caught off guard. For instance, before the pandemic, the use of face masks, which is one of the primary protection against the virus, ${ }^{21}$ was only practiced for healthcare activities and in some Asian countries, but it was not part of the majority's lifestyle. ${ }^{22}$ During the early spread of the virus, different groups of people even refused to wear face masks due to cultural reasons. ${ }^{22}$ However, now that the fight against COVID-19 asserted its way to every culture, wearing a face mask ${ }^{23}$ has become a symbol that signifies solidarity ${ }^{24}$ with the battle against the virus. This example shows the power that culture has in terms of mobilizing people to act.

What is not part of culture is also most likely to elude the consciousness of many. Having a culture that is mindful of this matter, prior to the pandemic, could have saved the world from all the trouble. Hopefully, this pandemic developed in us a culture that is cognizant of this situation and helps in preventing the same thing from happening again.

Religion has also been an important institution during the early transmission of the virus. The responses of various religious institutions were critical during the initial stages. In fact, WHO acknowledged this and even issued recommendations to guide religious groups and leaders in continuing their practices amidst the pandemic. $^{25}$ Transforming physical religious practices into virtual forms greatly helped the containment of the virus. 
Moreover, religion has also served as an effective avenue in transmitting accurate information that can reduce fear and stigma brought by the unfamiliarity of people to the nature of the virus. ${ }^{25}$

In addition, our problem with the COVID-19 began long before the first human transmission happened. The mutation of the virus did not just occur miraculously by sheer force of nature deprived of any human involvement. The ecological pressure caused by human activities made the virus jump from animal to man. ${ }^{26}$ Different human practices that encroach into animals' natural habitats forcefully lead to human transmission of the virus. Unnoticed by most, the efforts of various religions to ensure the public's safety predates even the first transmission of the virus. For instance, the Catholic Church, as early as 1971, has expressed concerns regarding the exploitation of nature and warned people that abusive actions will definitely turn against humanity. ${ }^{27}$ Just recently, in 2015, Pope Francis once again urged everyone to pay attention to the health of our common home to ensure the safety of everyone. $^{28}$ Unfortunately, despite these teachings, we still find ourselves faced with this global pandemic.

Culture and religion could only do so much during the early transmission of the virus. Who really bears the most crucial responsibility during this stage is the state or the government. Based on the current situation, proper government response during the preliminary phase of the spread could have changed the course of events. For instance, while the rest of the world was downplaying the threat of the virus, New Zealand was among the few countries that heightened its public health measures to contain the importation and spread of COVID-19, resulting in minimal reported cases. ${ }^{29}$ Along the way, the Philippine government also proposed a contactless form of greeting to avoid physical touch. ${ }^{30}$ The government's speedy response provided this country enough space to catch up with the virus. Furthermore, proper communication by the government proved itself consequential during this phase. The lack of government transparency hindered healthcare systems from preparing proper measures such as procuring essential supplies, ventilators, and test kits. ${ }^{26}$

Without a doubt, culture, religion and the state's initial reactions, whether of caution or indifference, greatly contained or contributed to the virus' transmission. Should another pandemic occur, these voices are worth listening to first as they work together with the field of public health.

\section{Management}

\section{Culture, Religion and the State Play a Vital} Role in Managing COVID-I9 Patients

Culture as a way of life is inseparable from the management of COVID-19 patients. Cultural beliefs and values play a part in the success of efforts to manage cases. So, culture must be considered in providing care and formulating new culture-related policies.

As culture is specific to a person or a group of persons, working with COVID-19 patients who come from different cultures may pose problems because of variations in race, language, and even nutrition. Culturally competent care is necessary to render appropriate service and reduce medical errors caused by cultural differences. ${ }^{31}$ Similarly, death and burial practices have also been changed to accommodate government policies. Each culture features its own way of burying their dead. ${ }^{32}$ For most cultures, death and burial is a formal passage from earthly to eternal life. ${ }^{33}$ However, these cultural manifestations have been compromised, especially when the death is related to COVID-19. Health protocols also restrict a family's grieving, even grieving their inability to grieve, ${ }^{34}$ as policies dictate that COVID-19 casualties be immediately cremated. Therefore, new culturally sensitive practices must be formulated, or the existing ones reformulated, so that the bereaved families are able to accept more easily the loss of a loved one.

As the crisis has highlighted the more and less adaptive cultures, it is necessary to build more fluid, inclusive and ethical cultures which are likely to thrive during a health crisis. Nevertheless, though culture must be considered, a cultural cure-all is almost impossible as each is founded on its own unique beliefs and values.

In countries with a religious majority, religion plays an influential role in managing COVID-19 patients. The cancellation of worship services and closure of churches put a huge strain on those who search for spiritual guidance in times like this. ${ }^{35}$ Many studies have revealed the importance of religiosity and spirituality in healthcare as it provides people with a level of stability and significance. ${ }^{36}$ Therefore, religion must fulfill its role by following quarantine protocols, such as lockdowns and physical distancing, determined by the state and transferring their services online, where there is virtually zero chance for transmission. Similarly, spiritual care must also be extended to healthcare workers, ${ }^{9}$ and to individuals who are isolated, including their families. ${ }^{12}$ During the 
pandemic, healthcare workers, isolated individuals, and their families are stereotyped and stigmatized as virus carriers. Being infected, or simply being associated, with the virus may greatly shake one's faith. Religious communities are right in making live-streamed services, communal prayers, recollections and retreats, and even processions, available to these people online. Religions must also provide new guidelines on the performance of rites and rituals that respond to the current situation. Special prayers, such as the oratio imperata (obligatory prayer) against COVID-19, must also be introduced and updated. $^{37}$

The role of religion in the management of patients with COVID-19 is underrated. Establishing a stronger relationship with a higher being may lead to less anxiety and stress, and heightened feelings of hope and stability, consequently improving one's immunity. ${ }^{38}$

The primary role of the state is in formulating policies for the benefit of most, if not all of, the population. These policies should be in consideration of all other areas of living affected by the pandemic, eg education, business, transportation, tourism, and their corresponding government agencies. The Philippine government, early on in the pandemic, established the Inter-Agency Task Force on Emerging Infectious Diseases (IATF-EID) ${ }^{39}$ True to its name, the IATF is composed of different government agencies, although its competence and overall effectiveness has always been put into question. ${ }^{40}$ Aside from formulating policies, the state should also be in charge of the implementation of such policies. A year into the pandemic, many have noticed how some citizens still do not follow the necessary health protocols ${ }^{41}$ such as the proper wearing of face masks and shields, and maintaining a physical distance. In addition, state-managed isolation facilities must also be established, instead of turning private homes into quarantine facilities, since management is more effective in these facilities. ${ }^{42}$ Finally, the state must also consider the "cautious and gradual" reopening of schools ${ }^{43,44}$ in order to give its citizens, at least, a semblance of normalcy.

Overall, citizens undeniably turn to the state for leadership and unity in times of crisis. Oddly, it is also during this time of crisis that the powers of the state are challenged, even critiqued, the most. It is necessary, therefore, that the state exercise its utmost power not only in responding to the health crisis, but also in protecting the rights of its citizens in order to, ultimately, reaffirm the idea that an effective response to the crisis is founded on a healthy citizen-state relationship. ${ }^{45}$

\section{Vaccination}

One of the most promising solutions to the COVID-19 pandemic is the formulation of vaccines. After a few months of clinical trials, the first mass vaccination program started in early December 2020, and millions of doses of vaccines have been administered. ${ }^{46}$ As COVID19 vaccines are readily available for public rollout, culture, religion and the state play a role in significantly influencing people's minds that these vaccines are safe and effective.

The role of culture, as a social norm, heterogeneously drives human behaviors ${ }^{47}$ in the deployment of COVID-19 vaccines. The state, which is primarily responsible for the vaccine rollout, has to take into serious consideration that culture is a contributory factor ${ }^{48}$ in this public health crisis. The presence of culture underscores that no people must be left behind in this vaccination program. Thus, the inclusion of the marginalized sector of society, ${ }^{49}$ such as indigenous people and ethnic communities, ${ }^{50}$ in the list of the government vaccination program is a form of cultural competence. In a way, cultural competence is the ability of health systems to provide care to patients with diverse values, beliefs, and behaviors by tailoring delivery to meet patients' social, cultural, and linguistic needs. ${ }^{51}$ Because of this, culture poses mature conversations with the concerned communities which have to be carefully considered in these trying times. In this sense, culture removes the barriers of exclusivity in this time of a pandemic. Hence, an awareness of culture is also an awareness of people. Promoting public health is inseparable from culture because human behaviors seem to be involved.

Another factor that could promote the safety and efficacy of COVID-19 vaccines is religion. Often, religion is placed on the other side of science. However, both science and religion are directed toward the benefit of humanity in this global health crisis. ${ }^{52}$ Various religions around the world could serve as powerful instruments for people to allay their doubts about the vaccines. Therefore, religion has a proper role in this pandemic since, as an institution, it can inspire positive social change. ${ }^{53}$ One concrete example is evident in the Philippines. Filipino Catholic bishops are willing to be vaccinated in public if the act will help establish confidence in the government's vaccine campaign and allay the public's fear of vaccination. Religion 
also encourages and provides means for people, especially the poorest of the poor, to get vaccinated. ${ }^{54}$ Thus, the immediate collaboration between government officials and religious leaders could be a big step in encouraging the people to participate in COVID-19 vaccination programs. If religious institutions can form a strong partnership with the government that promotes the need for vaccines, countries that are heavily influenced by religion will help people to believe in the safety and efficacy of the vaccines. $^{55}$

The main responsibility for the deployment of the COVID-19 vaccines is in the state. The responsibilities of the state for COVID-19 vaccines include determining allocations to critical populations, managing the systems for ordering, distributing and monitoring vaccines, supporting the administration of vaccines in a wide variety of healthcare and community settings, and engaging and communicating with communities in creative ways to address those who may face barriers to access or be hesitant to get the vaccine. ${ }^{55}$ One of the challenges faced by government officials nowadays is citizen's hesitancy to be vaccinated due to the vaccine's potential side effects. Thus, state officials are asked to establish public trust in their constituents, that their vaccination programs could be one of the solutions to end the pandemic. In order to achieve this, common good, public service ${ }^{56}$ and transparency ${ }^{57}$ must be evident in our government officials as they aim to establish public trust among citizens. In this manner, the state has to be a role model for its people to prove that the vaccination program could be the possible solution to end the pandemic.

While vaccines represent a promising solution to the COVID-19 pandemic, a call for a multidisciplinary approach to vaccination is greatly needed in this time of a global health crisis. Culture, religion and the state have a role and responsibility in the rollout of the COVID-19 vaccines. The work of these three distinct but complementary sectors poses a promising COVID-19 vaccination program that could give light to an alternative future ${ }^{58}$ a return to a sense of normalcy that we can share.

\section{Conclusion}

In this paper, we discussed that since the coronavirus affected multiple facets of human life, there is a call for a multidisciplinary approach, involving a concerted effort among culture, religion and the state, towards ensuring public health during the COVID-19 pandemic. We determined that culture, religion and the state can all help in addressing relevant concerns. More inclusive and resilient cultural manifestations must be formulated. Wearing face masks and reformulating burial practices were some of the examples that showcase the importance of culture in responding to the pandemic. In addition, religions must adapt to the current situational needs while assuring their followers' spiritual health. Religions have done this by continuously providing guidelines and spiritual support to people using various forms. Lastly, the state has the primary obligation in formulating and implementing policies toward an effective crisis response. Regulation of people's behavior, legislating necessary laws, and employing proper COVID-19 response are some of the evidence of this. Thus, this call for a multidisciplinary approach which we propose in handling the COVID-19 pandemic is essential since it can also serve as a model for any public health crisis in the future.

\section{Funding}

No funding was received for this paper.

\section{Disclosure}

The authors declare no conflicts of interest for this work.

\section{References}

1. World Health Organization. WHO director-general's opening remarks at the media briefing on COVID-19-11 March 2020; 2020. Available from: https://www.who.int/director-general/speeches/detail/who-direc tor-general-s-opening-remarks-at-the-media-briefing-on-covid-1911-march-2020. Accessed February 27, 2021.

2. Rufai SR, Bunce C. World leaders' usage of Twitter in response to the COVID-19 pandemic: a content analysis. J Public Health. 2020;42 (3):510. doi:10.1093/pubmed/fdaa049

3. Neal K. The collateral damage of COVID-19. J Public Health. 2020;42(4):659. doi:10.1093/pubmed/fdaa208

4. Ekzayez A, al-Khalil M, Jasiem M, et al. COVID-19 response in northwest Syria: innovation and community engagement in a complex conflict. J Public Health. 2020;42(3):507. doi:10.1093/pubmed/ fdaa068

5. Hamaguchi R, Nematollahi S, Minter DJ. Picture of a pandemic: visual aids in the COVID-19 crisis. J Public Health. 2020;42(3):485. doi:10.1093/pubmed/fdaa080

6. Bäuerle A, Teufel M, Musche V, et al. Increased generalized anxiety, depression and distress during the COVID-19 pandemic: a cross-sectional study in Germany. $J$ Public Health. 2020;42(4):675. doi:10.1093/pubmed/fdaa106

7. Holmes EA, O'Connor RC, Perry VH, et al. Multidisciplinary research priorities for the COVID-19 pandemic: a call for action for mental health science. Lancet Psychiatry. 2020;7:547-560.

8. Chirico F, Magnavita N. The crucial role of occupational health surveillance for health-care workers during the COVID-19 pandemic. Workplace Health Saf. 2021;69(1):5-6. doi:10.1177/ 2165079920950161

9. Sarmiento PJD. Wounded healers: a call for spiritual care towards healthcare professionals in time of COVID-19 pandemic. $J$ Public Health. 2020;43:e273-e274. doi:10.1093/pubmed/fdaa232 
10. Chirico F, Nucera G. An Italian experience of spirituality from the coronavirus pandemic. J Relig Health. 2020;59(5):2193-2195. doi:10.1007/s10943-020-01036-1

11. Muldong VM, Garcia AE Jr, Gozum IEA. Providing psychosocial support for work-from-home educators during the COVID-19 pandemic. J Public Health. 2021;43:e334-e335. doi:10.1093/pubmed/ fdab039

12. Galang JRF. Pastoral and spiritual care for quarantined individuals and their families. J Public Health. 2021;43:e350-e351. doi:10.1093/ pubmed/fdab061

13. Gozum IEA, Capulong HGM, Galang JRF, Gopez JMW. An ayuda to the least advantaged: providing a program for those who were hit the hardest during the COVID-19 pandemic. J Public Health. 2021;43: e317-e318. doi:10.1093/pubmed/fdab014

14. Chirico F, Sacco A, Nucera G, Magnavita N. Coronavirus disease 2019: the second wave in Italy. $J$ Health Res. 2021;35(4):359-363. doi:10.1108/JHR-10-2020-0514

15. Baena-Díez JM, Barroso M, Cordeiro-Coelho SI, et al. Impact of COVID-19 outbreak by income: hitting hardest the most deprived. $J$ Public Health. 2021;42(4):698. doi:10.1093/pubmed/fdaa136

16. Harlem G. Descriptive analysis of social determinant factors in urban communities affected by COVID-19. J Public Health. 2020;42 (3):468. doi:10.1093/pubmed/fdaa078

17. Chirico F. Vaccinations and media: an on-going challenge for policy makers. J Health Soc Sci. 2017;2(1):9-18. doi:10.19204/2017/vccn1

18. Lucia VC, Kelekar A, Afonso NM. COVID-19 vaccine hesitancy among medical students. J Public Health. 2020. doi:10.1093/pubmed/fdaa230

19. Vergara RJD, Sarmiento PJD, Lagman JDN. Building public trust: a response to COVID-19 vaccine hesitancy predicament. J Public Health. 2020;43:e291-e292. doi:10.1093/pubmed/fdaa282

20. World Health Organization. Pneumonia of unknown cause - China; 2020. Available from: https://www.who.int/csr/don/05-january-2020pneumonia-of-unkown-cause-china/en/. Accessed March 29, 2021.

21. World Health Organization. Coronavirus disease (COVID-19) advice for the public: when and how to use masks; 2021. Available from: https://www.who.int/emergencies/diseases/novel-coronavirus-2019/ advice-for-public/when-and-how-to-use-masks?gclid= CjwKCAjwu5CDBhB9EiwA0w6sLf_P4j4_cnnqHV21Uczpn_ V4M5m_6brj1FNNs15rSR6sVCihcT6_KxoC2ZAQAvD_BwE. Accessed March 29, 2021.

22. Tateo L. Face masks as layers of meaning in times of COVID-19. Culture Psychol. 2021;27(1):131-151. doi:10.1177/1354067X20957549

23. Azimi AV, Makvandi S, Karimi L. Cultural reasons: the most important factors in resisting wearing a mask. Hospital Practices Res. 2020;5(3):120-121. doi:10.34172/hpr.2020.23

24. Galang JRF, Gopez JMW, Capulong HGM, Gozum IEA. Solidarity as a companion virtue in response to the COVID-19 pandemic. $J$ Public Health. 2021;43:e315-e316. doi:10.1093/pubmed/fdab024

25. World Health Organization. Practical considerations and recommendations for religious leaders and faith-based communities in the context of COVID-19; 2020. Available from: https://www.who.int/publications/i/ item/practical-considerations-and-recommendations-for-religious-lea ders-and-faith-based-communities-in-the-context-of-covid-19?gclid= CjwKCAjwu5CDBhB9EiwA0w6sLWbL0keQfBMj9cHI-pH_ NvmVmnfQjQrWrnUKa2x_ZF5-rcPb6JGWthoCWhcQAvD_BwE. Accessed March 29, 2021.

26. Keni R, Alexander A, Nayak PG, et al. Covid-19: emergence, spread, possible treatments, and global burden. Front Public Health. 2020;8:216. doi:10.3389/fpubh.2020.00216

27. Paul VI. Octogesima adveniens. Vatican City; 1971. Available from: vatican.va/content/paul-vi/en/apost_letters/documents/hf_p-vi_apl_ 19710514_octogesima-adveniens.html. Accessed March 29, 2021.

28. Francis. Laudato Si. Vatican City; 2015. Available from: http://www. vatican.va/content/francesco/en/encyclicals/documents/papa-fran cesco_20150524_enciclica-laudato-si.html. Accessed March 29, 2021.
29. World Health Organization. New Zealand takes early and hard action to tackle COVID-19; 2020. Available from: https://www.who.int/wes ternpacific/news/feature-stories/detail/new-zealand-takes-early-andhard-action-to-tackle-covid-19. Accessed March 29, 2021.

30. Gopez JMW, Capulong HGM, Galang JRF, Gozum IEA. 'Bating Filipino': contactless greeting during the COVID-19 pandemic. $J$ Public Health. 2021;43:e313-e314. doi:10.1093/pubmed/fdab027

31. Lomiguen CM, Rosete I, Chin J. Providing culturally competent care for COVID-19 intensive care unit delirium: a case report and review. Cureus. 2020;12(10):e10867. doi:10.7759/cureus.10867

32. Rathod S. Impact of culture on response to COVID-19. BMJ. 2020. doi:10.1136/bmj.m1556

33. Sarmiento PJD. Changing landscapes of death and burial practices: public health response in time of COVID-19 pandemic. $J$ Public Health. 2020;43:e267-e268. doi:10.1093/pubmed/fdaa211

34. Gopez JMW. Hope as fundamental human response to loss and grief experiences in the time of COVID-19. J Public Health. 2021;43: e332-e333. doi:10.1093/pubmed/fdab042

35. Del Castillo FA, Biana HT, Joaquin JJ. ChurchInAction: the role of religious interventions in times of COVID-19. J Public Health. 2020;42(3):633-634. doi:10.1093/pubmed/fdaa086

36. Rovers M, Kocum L. Development of a holistic model of spirituality. $J$ Spiritual Ment Health. 2010;12(1):2-24. doi:10.1080/ 19349630903495475

37. Gomes R. Manila Archdiocese braces for 'worst case' scenario. Vatican News; 2020. Available from: https://www.vaticannews.va/ en/church/news/2020-03/philippines-manila-archdiocese-corona virus-pabillo.html. Accessed March 29, 2021.

38. Chirico F. Spiritual well-being in the 21st century: it is time to review the current WHO's health definition. J Health Soc Sci. 2016;1(1):1116. doi:10.19204/2016/sprt2

39. Kabagani LJ. Containing covid 19, mitigating impacts. philippine news agency; 2020. Available from: https://www.pna.gov.ph/arti cles/1125726. Accessed March 29, 2021.

40. Ramos CM. Drilon hits DOH, IATF for 'never-ending failure'. Philippine Daily Inquirer; 2021. Available from: https://newsinfo. inquirer.net/1409741/maraming-namamatay-sa-incompetence-nila-dri lon-hits-doh-iatf-for-never-ending-failure. Accessed March 30, 2021.

41. De Vero MKB, Gozum IEA, Melad AM. Prevention and planning as important factors in ensuring public health in the Philippines during the COVID-19 pandemic. J Public Health. 2021;43:e358-e359. doi:10.1093/pubmed/fdab058

42. Lopez M, Gallego C, Abós-Herrándiz R, et al. Impact of isolating COVID-19 patients in a supervised community facility on transmission reduction among household members. J Public Health. 2021. doi:10.1093/pubmed/fdab002

43. Sarmiento PJD, Sarmiento CL, Tolentino RL. Face-to-face classes during COVID-19: a call for deliberate and well-planned school health protocols in the Philippine context. $J$ Public Health. 2021;43:e305-e306. doi:10.1093/pubmed/fdab006

44. Gopez JMW. Cautious and gradual reopening of limited face-to-face classes in Philippine tertiary schools. J Public Health. 2021;43:e356e357. doi:10.1093/pubmed/fdab060

45. United Nations Department of Economic and Social Affairs. UN/DESA policy brief \#75: COVID-19: reaffirming state-people governance relationships; 2020. Available from: https://www.un.org/development/desa/ dpad/publication/un-desa-policy-brief-75-covid-19-reaffirming-state-peo ple-governance-relationships/. Accessed March 29, 2021.

46. World Health Organization. Coronavirus Disease (COVID-19): vaccines; 2020. Available from: https://www.who.int/news-room/q-adetail/coronavirus-disease-(covid-19)-vaccines? adgroupsurvey=

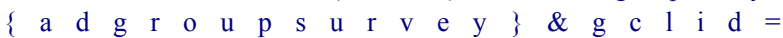
Cj0KCQjw9YWDBhDyARIsADt6sGZHY1YL6rMuGZxnWAvajE q_GVnbdlLzdPJ9SnB1LvV1SQKeN_-O-O0aAkK3EALw_wcB. Accessed March 29, 2021. 
47. Huynh TLD. Does culture matter social distancing under the COVID-19 pandemic? Saf Sci. 2020;130:104872. doi:10.1016/j.ssci.2020.104872

48. Lagman JDN, Vergara RJD, Sarmiento PJD. Culture as a contributory factor in combatting the Covid-19 pandemic. J Public Health. 2021;43:e289-e290. doi:10.1093/pubmed/fdaa280

49. Braganza BB, Capulong HGM, Gopez JMW, et al. Prioritizing the marginalized in the COVID-19 vaccine rollout. J Public Health. 2021;43:e368-e369. doi:10.1093/pubmed/fdab083

50. Sarmiento PJD, Serrano JP, Ignacio RP, et al. No indigenous peoples left behind on the rolling out of COVID-19 vaccines: considerations and predicaments. J Public Health. 2021;43:e321-e322. doi:10.1093/ pubmed/fdab032

51. Hanif W, Ali SN, Patel K, Khunti K. Cultural competence in covid19 vaccine rollout. BMJ. 2020;m4845. doi:10.1136/bmj.m4845

52. Pacaol NF, Perez JM. (Filipino) people and religion, science and government: an interactive approach against COVID-19 pandemic. J Public Health. 2021;43(2):e391-e392. doi:10.1093/pubmed/fdab105

53. Berezow A. Building trust: how the church can encourage COVID vaccines. American Council on Science and Health; 2021. Available from: https://www.acsh.org/news/2021/03/03/building-trust-how-church-canencourage-covid-vaccines-15382. Accessed March 29, 2021.
54. Gopez JMW. Building public trust in COVID-19 vaccines through the catholic church in the Philippines. J Public Health. 2021;43: e330-e331. doi:10.1093/pubmed/fdab036

55. National Governors Association. State COVID-19 vaccine resources; 2021. Available from: https://www.nga.org/center/publications/statecovid-19-vaccine-resources/. Accessed March 29, 2021.

56. Gozum IEA. Common good and public service as vital components for government officials in promoting COVID-19 vaccination. $J$ Public Health. 2021;43:e311-e312. doi:10.1093/pubmed/fdab025

57. Dela Cruz MDM, Mendoza AJM, Gueco GEA, et al. Transparency of the national government as key in promoting the rollout of COVID-19 vaccines. J Public Health. 2021;43:e381-e382. doi:10.1093/pubmed/fdab092

58. Schoch-Spana M, Brunson EK, Long R, et al. The public's role in COVID-19 vaccination: human-centered recommendations to enhance pandemic vaccine awareness, access, and acceptance in the United States. Vaccine. 2020. doi:10.1016/j.vaccine.2020.10.059
Risk Management and Healthcare Policy

\section{Publish your work in this journal}

Risk Management and Healthcare Policy is an international, peerreviewed, open access journal focusing on all aspects of public health, policy, and preventative measures to promote good health and improve morbidity and mortality in the population. The journal welcomes submitted papers covering original research, basic science, clinical \& epidemiological studies, reviews and evaluations,

\section{Dovepress}

guidelines, expert opinion and commentary, case reports and extended reports. The manuscript management system is completely online and includes a very quick and fair peer-review system, which is all easy to use. Visit http://www.dovepress.com/testimonials.php to read real quotes from published authors. 